\section{TO PROVIDE AN OVERVIEW OF THE WORKING GROUP ON OCCUPATIONAL INFECTIOUS AGENTS' RESEARCH AND AN OPPORTUNITY TO INITIATE GUIDANCE PRODUCTS}

${ }^{1}$ Mary H Ross ${ }^{*}$, ${ }^{2}$ Claudina M Nogueira. ${ }^{1}$ University of the Witwatersrand, Johannesburg, South Africa; ${ }^{2}$ University of Pretoria, Pretoria, South Africa

\subsection{6/oemed-2018-ICOHabstracts.589}

${ }^{1}$ Prof. Albert Nienhaus, ${ }^{2}$ Prof. Robert R. Orford, ${ }^{3}$ Prof. Stefano Porru, ${ }^{4}$ Prof. Kari Reijula, ${ }^{5}$ Prof. Thomas P. Fuller

${ }^{1}$ University Clinics Hamburg-Eppendorf (UKE), Health Services Research in Nursing (CVcare), Hamburg, Germany

${ }^{2}$ Division of Preventive, Occupational, and Aerospace Medicine, Mayo Clinic, Scottsdale, Arizona, USA

${ }^{3}$ Department of Diagnostics and Public Health, University of Verona, Verona, Italy

${ }^{4}$ Professor of Occupational Health, Helsinki University, Helsinki, Finland

${ }^{5}$ Illinois State University, Normal, Illinois, USA

\section{$1603 a$ COSTING OCCUPATIONAL INFECTIONS: LESSONS FROM HEPATITIS C IN HEALTH WORKERS IN GERMANY}

${ }^{1} \mathrm{~A}$ Nienhaus, ${ }^{2} \mathrm{C}$ Westermann, ${ }^{2} \mathrm{M}$ Dulon. ${ }^{1}$ University Clinics Hamburg-Eppendorf (UKE), Hamburg, Germany; ${ }^{2}$ Statutory Accident Insurance and Prevention in the Health and Welfare Services (BGW), Hamburg, Germany

\subsection{6/oemed-2018-ICOHabstracts.590}

Introduction Healthcare personnel (HCP) have a risk of hepatitis C infection (HCI). Chronic HCI is associated with significant morbidity and mortality. The aim of this study is to describe the cost for occupationally-caused HCI based on data from an accident insurance carrier.

Methods The secondary data analysis used the database of the German Institution for Statutory Accident Insurance and Prevention in the Health and Welfare Services. The analysis is based on a sample of HCP whose HCI were registered as occupational diseases (OD) between 1996 and 2013. Incurred cost was calculated for the period between 1 January 2000 and 31 December 2014.

Result The number of registered ODs declined by $86 \%$ within the study period. A total of 1.121 ODs were registered. The majority was female, older than 40 years and medical nursing professionals. In the study period, the cost came to a total of $€ 87.9$ million, of which $60 \%$ was attributable to pension payments $(€ 51,570,830)$ and around $15 \%$ was attributable to medical treatment (€12,978,318). Expenses for drugs increased in 2012 (from around $€$ 500,000-8 00000 to $€$ 1.7 million) and 2014 (to $€ 2.5$ million). Pension payments came to $€ 1.6$ million in 2000 and rose continuously to over $€ 4$ million in 2014. Expenses for occupational rehabilitation accounted for less than $1 \%$.

Discussion For HCI as an OD, an increase in cost has been observed in recent years, while the number of registered cases has declined. This rise in cost is explained by the increase in pension payments and, since 2012, by a rise in the cost for drugs. In future the high cost of anti-viral therapies is potentially compensated by treatment benefits and savings for pension payments.

\section{3b TRAVEL AND THE SPREAD OF INFECTIOUS DISEASES}

RR Orford. Division of Preventive, Occupational, and Aerospace Medicine, Mayo Clinic, Scottsdale, Arizona, USA

\subsection{6/oemed-2018-ICOHabstracts.591}

Introduction Over three billion passengers fly internationally each year, including executives, professionals and workers employed in many industries. Government and non-government organisations such as the US Centres for Disease Control (CDC), the International Civil Aviation Organisation (ICAO) and its Collaborative Arrangement for the Prevention and Management of Public Health Events in Civil Aviation (CAPSCA), and the World Health Organisation (WHO), working individually and together, have recommended interventions to prevent the occurrence of infectious disease outbreaks resulting from travel, particularly air travel.

Methods Measures recommended to prevent the spread of infectious diseases associated with travel were reviewed, and preventive interventions recommended for individual infectious diseases were assessed with respect to their effectiveness.

Result Public travel information and monitoring of exposed travellers are the most cost effective measures for preventing the spread of travel-related infectious diseases. Handwashing and the use of face masks may reduce transmission to others, but have limited value as protective measures for individual travellers. Entry and exit screening are commonly used and have some effectiveness, particularly with respect to alerting the public of specific infectious disease risks, but are expensive, and will miss cases in the incubation period when there are no symptoms or fever. Contact tracing may be of benefit particularly with respect to monitoring of exposed passengers, but can also be expensive, passenger manifests may be incomplete, and exposed passengers may be difficult to locate several days after arrival at their destination. Control of animals and fomites (baggage, cargo, etc.) has limited value. Travel restriction is of limited effectiveness and politically controversial. Quarantine is costly, and compliance difficult to enforce.

Discussion Preventive measures are used to prevent or delay the spread of infectious diseases resulting from travel, but are of variable effectiveness. Public travel information and monitoring of exposed travellers are the most effective control measures.

\section{C IMMUNISATION POLICIES AND PRACTICES IN OCCUPATIONAL HEALTH: EVIDENCE AND OPTIONS FROM THE LITERATURE AND THE FIELD}

S Porru, M Chiappin, N Sfriso. University of Verona, Verona, Italy

\subsection{6/oemed-2018-ICOHabstracts.592}

Introduction Exposure to biological agents occurs in many workplaces. Immunisation is a safe, cost-effective intervention for Vaccine Preventable Diseases (VPD). Although updated, evidence-based vaccination policies are available for the general population, overall there are few consensus recommendations for working populations apart from health care workers (HCWs).

Methods To evaluate current trends and evidence-based options, we performed a literature review of main online databases from 1997 to 2017, websites of various public 
health organisations, and professional societies, focusing on vaccination policies and practices in occupational settings.

Result Many vaccines are available for workers exposed to certain biological agents, while others are imminent. However, systematic, representative data on occupational immunisation policies, practices and coverage are lacking. Most pertain to HCWs, Influenza and HBV and coverage is sub-optimal. Variations exist by country and region for legislation, policies, schedules, groups requiring vaccination, implementation. Relevant issues include: access to vaccines; cost-effectiveness; immunisation coverage; identification susceptible of workers at-risk; fitness for work; involvement of all stakeholders.

Discussion Immunisation is an additional preventive tool to conventional workplace interventions, very effective for biohazard containment. A specific immunisation policy and practice is a strategic priority for individual workers, different workforces and the public health system. The main Occupational Health Professionals' (OHP) responsibilities are: individual, activity and area risk assessment; evaluation and provision of cost-effective vaccines; obtaining consent (or refusal) following counselling; managing non-responders and those who refuse vaccinations; career guidance; remaining updated. Mandatory immunisation should be explored in selected circumstances. OHP, employers and workers share the responsibility to implement the WHO Global Vaccine Action Plan to expand access to immunisation to all susceptible workers and strengthen routine immunisation. Policies and services should reside in the realm of Corporate Social Responsibility and be harmonised across industries, regions and countries with the ultimate goal to control and eradicate VPD in workplaces.

\section{3d OCCUPATIONAL INFECTIOUS AGENTS (OIA) IN HOSPITAL FACILITIES - INTERFACE BETWEEN OCCUPATIONAL AND PUBLIC HEALTH}

K Reijula. Professor of Occupational Health, Helsinki University, Helsinki, Finland

\subsection{6/oemed-2018-ICOHabstracts.593}

Introduction Mainly due to epidemic infections such as SARS and avian influenza, exposure prevention to occupational infectious agents (OIA) has become of increasing interest in hospitals. New models of action between different professionals in hospitals and improving the competence of hospital workers are urgently needed.

Methods Attitudes, knowledge and skills of hospital workers, action models in preventing OIA exposure and the performance of isolation rooms in preventing the spread of microbes in patient wards were assessed in Finnish hospitals. Multi-professional team work between personnel in hospitals and health care (both occupational and public health) but also with the management of hospital facilities were evaluated.

Result Best results in preventing exposure to OIA were found in hospitals where the competence of personnel was high and the staff was committed to use the best practices of exposure prevention. The quality in the performance of isolation rooms played a significant role in results. Close collaboration between occupational health and the staff of infectious diseases but also with public health was found necessary in improving the processes of exposure prevention.

Discussion Multi-professional collaboration between occupational health, the personnel of infectious diseases and public health seems to have a significant role in preventing exposure to OIA. Health care professionals need also to work together with the management of facilities to improve the quality of indoor environment and the performance of isolation rooms. The attitudes and competence of hospital staff in association with good performance of isolation rooms in hospitals are critical related to occupational safety and health of hospital workers.

\section{3e INNOVATIONS IN INDUSTRIAL HYGIENE APPROACHES TO INFECTION CONTROL}

TP Fuller. Illinois State University, Normal, Illinois, USA

\subsection{6/oemed-2018-ICOHabstracts.594}

Introduction Healthcare Acquired Infections (HAIs) continue to pose a major burden on healthcare facilities around the world with major human and financial consequences. Furthermore, infectious diseases acquired while on-the-job continue to be a significant cause of morbidity and fatality of healthcare workers. It is difficult to deny that more needs to be done to control hazardous infectious agents and protect patients and workers from exposure.

Methods Industrial hygiene approaches to environmental and workplace hazardous infectious agents including anticipation, recognition, evaluation, and control were used as the foundation to re-evaluate infectious agents in the healthcare environment. The latest advances in the industrial hygiene hierarchy of controls were investigated including engineering, administrative measures, and the use of Personal Protective Equipment.

Result The field of industrial hygiene has been expanding at a rapid pace to support the needs of infection control in healthcare. New technologies are being demonstrated and implemented on several fronts. The ability of hospitals to protect patients by reducing HAIs can be influenced by the ability to effectively utilise the new industrial hygiene approaches to infection control. In addition to protecting patients, the likelihood of worker infections will also be reduced.

Discussion Industrial hygiene approaches to infection control in healthcare are sometimes misunderstood and often underutilised. The advantages of integrating new technologies in identifying, and then destroying infections agents in the hospital environment, demonstrates significant potential for protecting both patients and workers from communicable diseases acquired in the healthcare system.

\section{HOSPITAL LENGTH OF STAY AND ASSOCIATED FACTORS AMONG CONFIRMED INFLUENZA PATIENTS ADMITTED IN KING ABDULAZIZ MEDICAL CITY, WESTERN SAUDI ARABIA}

${ }^{1}$ Fayssal Farahat*, ${ }^{1}$ Mohammed Abd Al Aziz* ${ }^{1}$ Omaima Hassan*, ${ }^{1}$ Asim AlSaedi ${ }^{*}$, ${ }^{2}$ Majid AlShamrani*. 'Infection Prevention and Control, King AbdulAziz Medical City, Jeddah; ${ }^{2}$ Infection Prevention and Control Program, Ministry of National Guard

\subsection{6/oemed-2018-ICOHabstracts.595}

Introduction Influenza can cause mild to severe illnesses and serious outcomes can result in hospitalisation or death. Clinical presentation and management of influenza cases in Saudi Arabia have been tackled especially during 2009 H1N1 pandemic, however, available data on influenza related hospital stay and determining factors in the country is limited. This study aims to assess factors that determine the length of stay 